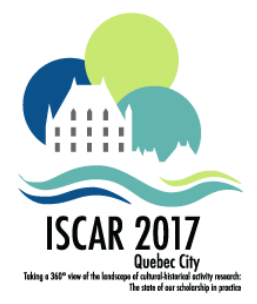

\title{
New Methodological View of Vygotsky
}

\author{
Stanislav M. Morozov \\ Moscow State University of Psychology and Education \\ Moscow, Russia
}

STANMOR@YANDEX.RU

\begin{abstract}
In order to see the true value of the cultural-historical psychology, one may need to view Vygotsky's scholarly endeavor as translational motion, in the course of which earlier developments become natural constituents of the later ones. During the first years of his academic career, Vygotsky introduced a number of important assumptions that he developed later in his theory of verbal thinking, which he had no chance to finish: the subject of Psychology is the process of people's interaction with their social environment; the driving force of the intrapsychic world's development is self-development which is based on a contradiction between meaning and sense; the person who gives birth to meanings is a totally new creature, i.e. a totally new subject of Natural Science. Careful examination of Vygotsky's ideas leads us to a number of assumptions that introduce drastic changes to our understanding of the subject of psychological research. Thus, Vygotsky's cultural-historical psychology seems to be a system that contains a significant methodological potential, rather than just a scientific theory.
\end{abstract}

Keywords : Vygotsky; Subject of psychology; Postnonclassical science. 
The world psychological community draws ever more attention to the work of the remarkable Soviet psychologist L. S. Vygotsky. However, Vygotsky is often treated as a psychologist who has created, albeit interesting, but just one of many psychological theories. In our opinion, this approach to the cultural-historical theory is a consequence of a serious underestimation of Vygotsky and his followers, among whom I would give the first place to A. N. Leontiev.

Unfortunately, most psychologists turn to, of course, an important, but not the only, concepts created by L. S. Vygotsky at the turn of the 20s-30s the last century: interiorization, the highest mental functions, a zone of proximal development. Less attention is drawn to the theoretical propositions expressed by Vygotsky at the very end of life: in the book Thinking and Speech and, most importantly, in the last chapter of this book.

To understand the theory of speech thinking, L. S. Vygotsky's scientific activity should be viewed as a steady movement from an almost behavioral approach that is characteristic for Vygotsky, who arrived from Belorussia to Moscow in 1924 and became an employee of the Moscow Psychological Institute, to an existentialist view of the inner world of man, what was expressed in the last years of his life. Between these two points (the initial and final) is the period (1927-30), in which was formulated the above are so popular today concepts. But the author of cultural-historical psychology, he lived for another four years, which are considered by many psychologists as a simple quantitative development of ideas formulated before 1930.In our opinion, the movement of Vygotsky's scientific thought is not a transition from one (exhausted) position to another, i.e. from theory to theory. This movement is a progressive development, during which earlier developments become organic constituents of later ones. this implies that it 's impossible to understand all the parts of Vygotsky's psychological system if we forget about the organic connection of all its elements.

\section{The subject of psychology in the theory of interiorization.}

L. S. Vygotsky came to psychology in the years of severe crisis that shook our science. It was a time of enhanced searches of the subject area, which psychologists should deal with. There were new psychological schools, insisting on their rightness. I stress: the psychological schools, which modern textbooks tell, differ qualitatively from the traditional understanding of the term "scientific school". A scientific school in the traditional sense is a group of researchers who are engaged "part" of the subject area. Psychologists in the early twentieth century were argued about what the object of psychology is: consciousness, unconscious, gestalt, behavior, etc. Cultural-historical psychology also offers its own idea of what psychology should.

L. S. Vygotsky said: it's not about the number of schools. The fact is that these schools don't have an adequate methodological basis. To overcome the crisis, we need a new methodology, which can only be Marxism. In this way, Vygotsky has initiated the construction of the so called cultural-historical psychology. 
In the first years of his work in Moscow, L. S. Vygotsky makes a number of important provisions, which later became the basis of his ideas about the subject of psychology:

- Qualitative difference of the subject of psychology.

L. S. Vygotsky came to Moscow as a researcher who had kept in the methodology of the Marxist version of Hegelianism. Vygotsky arrived in Moscow formed a researcher adheres to the methodology of the Marxist version of the Hegelian, and in the specific scientific field - a peculiar version of behaviorism. Today, such a set may seem eclectic, but the fact of the matter is that Vygotsky's behaviorism was based on the idea of including a person's consciousness in the reflex circuit. In Vygotsky's opinion, the task of psychology is to find qualitative differences in human reflexes. And really, the similarity of man with other living entities is the ability to respond to changes in the environment. However, human's reaction are qualitatively (and not quantitatively) different from those of a frog or amoeba. It means the need to search for special laws, which the person follows.

- Naturalness of the subject of psychology.

L. S. Vygotsky is convinced: psychology can only be a section of natural science. But not because psychology must engage of an objective subject with the help from experiment. Such positivistic views always caused Vygotsky serious doubts. Vygotsky denied the ideas of behaviorists who considered natural science as such a psychology that allows them to predict and control behavioral acts and gestalt psychologists who wanted to create a natural-science metatheory like physics. Vygotsky himself saw the scientific meaning of psychology precisely in the naturalness of its subject matter.

Under the naturalness of the object, L. S. Vygotsky understood his ability to selfdevelopment and the presence of two components in such a natural object: real and spiritual. Thus, according to Vygotsky, the subject of natural science is a living system. Apparently, such an interpretation should cause confusion among most modern representatives of natural science. However, such doubts, in our opinion, can be overcome by referring to Vygotsky's ideas about the method of psychology.

The method of psychology should be the analysis of psychological units, i.e. such tiny "particles" of the subject, in which the main properties (ie, attributs) of the subject of psychology were contained. At the same time, we musn't forget that L. S. Vygotsky's speech is not only about units, but also about the cells of psychological analysis, i.e. About the original forms of the inner world of man. Thus, we come to the notion of a man as a self-developing system that has received its present identity through the transformation of the oldest forms. And this means that any "particle" of live must contain the parent form of consciousness. We thus come to the peculiar panpsychism, for which it is not the presence of consciousness that is characteristic, but some qualities that it would be logical to call its parent forms. Thus, we come to the conclusion about a living and spiritualized nature in all forms of its existence. 
- The inbornness of the subject of psychology.

In the theory of interiorization L. S. Vygotsky distinguishes two lines of the child's mental development - "natural" ("inborn") and "cultural" development. Often these two lines are interpreted by psychologists as a ratio between the biological and social, which leads to the conclusion that the creator of cultural-historical psychology believes that the child is born as a biological being that becomes social (cultural) in the process of socialization.

In our opinion, the relationship between the natural and the social in L. S. Vygotsky looks different. A newly born person with all its set of functions (including mental ones) is not at all a biological being naturalized, but biological. In order to understand what is at issue, it is enough to recall that Vygotsky contrasts the concepts "biological" and "natural": the subject of Marxist psychology is natural, but not biologic. Biological, of course, participates in the development of higher mental functions, but in so far as the social participates in the organic development of man. Let's pay attention to how Vygotsky carefully uses the terms "natural" and "biological" when he talks about mental functions: natural - yes, but never biological. Psychology should be regarded as a natural science, but not as the biology section.

Of course, all this does not mean denying the problem of the relationship between social and biological. Moreover, one can clearly say that the organic development of the child involves two "factors": biological and social. However, L. S. Vygotsky answers the fundamental question of philosophical anthropology - the question of the relationship between biological and social determination of activity - using the principle of sublation, developed in the philosophy of Hegel. In accordance with this theory any level of development is a carrier of content preceding levels. "Genetically" earlier content in shot form is contained in younger formations. Hence, in particular, that the whole history of mankind is present in all of us. But each of us has this story amid its personal, individual experience. The old is present in the new, but is present in a hidden form. Here grows development methodology which was used by Vygotsky throughout all his life in psychology. The principle of sublation determines the ratio of higher mental functions and natural mental functions. We can say that the lower, elementary processes and patterns that govern them represent the processes of sublation.

There are several levels, determining the functioning of higher mental functions. Firstly, is biological level. Indeed, no one has ever seen a man (with his psyche, consciousness), which would not have certain biological traits (biological mass, a certain way of organized physiological structures, etc.). Secondly, it is "organic", i.e. the same biological components, but already before us as "acculturation". This organic maturation plays of a role than the engine of progress cultural development. Finally, it is actually the level of cultural behavior, which determines the flow of cultural forms of human behavior and is inherently social. It is characterized by cultural development of man as man.

L. S. Vygotsky explains in detail his position on the relationship between the biological and social - the ratio, which for him was equivalent to the correlation of lower and higher forms of behavior, lower and higher mental functions: the biological is sublated, preserved 
in the social, but not separated from the last as this ratio is often explained in modern psychological theories. Social, thus, is the dominant format of activity - a format that subordinates the biological.

All this leads us to the idea that the problem of "social or bio-logical" is not essential for the author of cultural-historical psychology. As a matter of fact, this is a problem of philosophical analysis, like any other problem of the correlation of "levels" of reality ("levels of the motion of matter", as Marxists call it). Man is neither biosocial, nor socio-biological, nor even biological education, but only social education.

\section{The subject of psychology in the theory of speech thinking.}

- Self-development of the subject of psychology.

By 1930, L. S. Vygotsky completed the construction of the theory of interiorization (part of which was the theory of higher mental functions). But the author of the cultural-historical theory lived another four years. And the rest of his time he devoted to the creation of the theory of an active, free man - the theory he set out in the last book, Thinking and Speech. Here Vygotsky does not limit himself to consideration of the process of interiorization, i.e. the transformation of the "external" into the "inner".

Apparently, the theory of interiorization he created does not fully satisfy the author. At the center of this theory is the "stimulus-tool", i.e. the instrument by which we mediate our interaction with nature. Having received the embodiment, the stimulus-tool becomes a sign, i.e. psychological tumor, mediating interaction of the components of our inner world. L. S. Vygotsky calls the inner world of man a psychological system, thereby emphasizing its integrity and non-additivity. Such a system, asserted Vygotsky, is subject to its inherent laws of dialectical formation, i.e. self-development.

But the theory of interiorization does not give an answer to the question: where does freedom begin, what are its sources? Hence L. S. Vygotsky's appeal to Hegel's philosophy. All nature, which, in the end, turns into an absolute spirit, according to Hegel, is a living organism. What is necessary, that the natural formation developed itself? Hegel believed that in every organism there are opposites that contradict one another. The struggle of such contradictory principles gives energy that allows the organism to develop. As Vygotsky says, if we find contradictory principles in the person himself, we will understand what freedom is. The subject of psychology is lively, and it must also contain contradictory formations. This is what Vygotsky begins to think about in the last years of his life. These reflections lead the author to construct a theory of speech thinking. Here the speech thinking is taken by the author as a model of the subject of psychology. In this process in the process of speech thinking - there is some element that contains the qualities of the whole subject of psychology. Such an element, in Vygotsky's opinion, is value as a process of transition from thought to word and back, i.e. the process of transition from outside to inside, and vice versa. Thus, Vygotsky introduces, along with interiorization, another 
mechanism - exteriorization. Not only from the outside, but also from the inner outside that's what the psyche is.

What in this process contradicts each other? When we transform our inner world into the form of the external world, we produce exteriorization. For example, a person, telling something, expresses his inner world outward. The listeners react in some way to the text they hear, and the narrator perceives these reactions of listeners. The inner world of the narrator changes, when information returns to him. Any interiorization is accompanied by such changes. This change constantly and continuously happens to all of us.

But that is not all. We are constantly interacting with the world. Peace for man is always people and things made by people. We communicate with people. And in the process of communication, we understand each other. The question arises: what is understanding? For the answer, take a word. Let it be the word "cow". What image arises in our consciousness when we hear this word? Every person has his own image. Someone has a cow "out of the textbook", giving milk, someone - a village in which this person saw a cow, someone has footage from a movie, etc. But when we talk to each other, all these images do not spill out. The fundamental limitation imposed by nature on man is the impossibility of a complete expression of the inner in the outer (words in sound, as L. S. Vygotsky would say).But we hear the word and understand each other. Hence, in our inner worlds there is something that unites us - something in common. This means that in our inner world there are two components coexisting: what unites me with other people (this component is suggested by Vygotsky as significance), and what belongs to me alone (this entity Vygotsky calls sense). Each of us has its own internal image (meaning). But in the external embodiment, our images are not identical to each other, since the experience of each of us is unique: not everyone has a grandmother in the village and not all watched the famous movie, and if they did, they did not necessarily remember what the other person remembered. But if we are able to understand each other (and we are capable of), then there is something in our inner world that unites us all. Hence, our inner world is twofold: it has something purely individual and something common to all. It consists, as philosophers say (and some psychologists, such as E. Fromm), from a certain A and not-A.

- Integrity of the subject of psychology.

In accordance with the theory of speech thinking, the inner world of man includes two components: meaning and significance. The contradiction between significance and meaning is the very driving force behind the formation (self-development) of the inner world of man. But these two components are not something close. This is integrity, i.e. the quality of an object, by which, what we had not shared such a holistic subject, always in each part we find two contrary components, i.e. the sense and significance. Thus L. S. Vygotsky (along with Hegel, Marx, Fromm, Heidegger, etc.) casts doubt on the law of identity formulated by Aristotle and which became the basis of the scientific worldview for millennia. If you believe Hegel, Marx, Husserl, Fromm, Vygotsky, this is not so: And not equal to yourself. 
- Sociality of the subject of psychology.

In the science of the nineteenth and early twentieth centuries, the atomist approach prevailed, according to which understanding is from simple to complex. We always consider social organisms to be more complex than biological organisms. Therefore, the traditional understanding of the subject of psychological research presupposed a transition from less complex biological elements to a more complex social whole.

L. S. Vygotsky resolutely passes from atomism to a holistic approach: to understand the biological, that is, the bodily component of a person we can only if we first examine the nature of the qualitative identity of the human being: first social, then biological - this must be the path of psychological research.

Thus, psychology should place at the beginning of its research not the consideration of the interaction of initially biological elements, in the process of their interaction generating the social essence of man, but the process of interaction of cultural and historical artifacts-an interaction that generates a new quality of human's parent forms, including its biological component.

The principle of development, which is fundamental in L. S. Vygotsky's theory, leads the author to another important thesis: man is only a social being. Of course, any proponent of the theory of development cannot ignore the biological component of man. But this does not mean that a person is a biological organism, which in the process of evolution has a new element - consciousness. In accordance with this logic, one could say that biological organisms are chemical elements with new biological constituents, and chemical elements - physical entities with chemical "additives". However, biologists have enough common sense not to call a frog a chemical-biological being, and chemists do not insist that the organic compound is a physico-chemical entity. The meaning of Vygotsky's theory, we believe, is that the status of a particular "subject" is determined not by its material components, but by those laws under which one or the other organic system. Man is guided only by social laws, and that is why he is a social being.

\section{- A new method of psychology.}

The inner world of man as a holistic formation is very difficult to know. The method of experiment is not suitable here. After all, the experiment is so conceived that it was possible to investigate some part of the subject. The experimenter purposely purifies the variables, i.e. decompose the whole into parts and study the selected "piece" of the subject. This "piece" of experimenters is called the "dependent variable". This variable should be properly "cleaned" so that no "additional variables" prevent us from "seeing" the selected part exactly. Clearing a variable means releasing it from all the influences of the external context, except those that are of interest to the experimenter. Researchers rarely think about the fact that among such discarded influences there are also those without which the organism under investigation simply does not exist in real life. These reflections lead L. S. Vygotsky to the necessity of constructing a special psychological method, which he calls the method of analysis by units. 
A unit of psychological analysis is the minimal "part" of the subject of psychology, containing the basic properties of this subject. L. S. Vygotsky illustrates this definition by an example borrowed from Gestalt psychologists. When a chemist has to study water, he does not study all the water available on Earth, but takes a water molecule. Having studied its properties, we learn the properties of all other water molecules. The psychological unit Vygotsky calls meaning. A little later, he introduces corrections: not the meaning, but the experience - that's what the unit, which contains the main components of the psychological process. Experience is a significance that is "saturated" with a person's emotions - an "affective field", as Vygotsky calls it.

\section{Prospects.}

The uniqueness of the person is most fully indicated by L. S. Vygotsky in the theory of speech thinking, which was never completed by the author. Nevertheless, the available statements of the author of cultural-historical psychology allow us to outline the prospects for the further construction of psychological science.

- Postnonclassicality of Vygotsky's theory.

L. S. Vygotsky's cultural-historical psychology is not just one of the scientific theories, but a methodological system that contains a significant potential for transforming the foundations of the world outlook of mankind. This is - postnonclassical science, if you use the terminology of the Soviet philosopher Stepin (2000).

V. S. Stepin proposed a special periodization of the development of science. In accordance with this classification, the classical period of development of science is replaced by "nonclassical", and then - "postnonclassical" science. Stepin conducted a study of the formation of the physical science of the twentieth century, when the so-called quantum physics, the physics of elementary particles, began to be created. Based on a thorough analysis of the works of scientists of that period - and Stepin was engaged in literally lineby-line research of texts, archives, drafts - the Russian philosopher comes to the following conclusions. At the stage of classical science, the subject was interpreted as an object independent of the researcher, and its goal was to search for objective truth. Nature here is seen as a simple mechanism, a model of which are mechanical devices. The heyday of such a science - XVII - sec. half. XIX centuries: from R. Bacon and R. Descartes to E. Mach.

At the beginning of the $20^{\text {th }}$ century, in science (first of all, in physics) a new nonclassical stage began. For this stage, it is characteristic that the researcher does not consider that the object exists by itself, regardless of the device by which the research is carried out. The device affects the results that we get. Such an "instrument" can be considered the scientist himself. Physicists have formulated this position in the form of the "principle of uncertainty" and the "principle of complementarity", when we can investigate either the mass or inertia of a particular body, depending on what the research setting is aimed at. 
The next stage of V. S. Stepin gave the title Post-non-classical science. Post-non-classical science deals with complex self-developing systems. One of its key features is the humanization of the object of research, i.e. the inclusion of man in the evolution of the world process (the anthropic principle). In other words, the reality of post-non-classical science is relations, connections and processes, in which a person is included. For post-non-classical sci-ence, global evolutionism and systemic character are characteristic, which can be combined into the principle of systemic historicism, as well as processual. The main principle of such a science is holism, in which subject-object dualism is erased. If at the previous stages of the formation of science the object is regarded as independent of the subject, now science begins to work not with the objects themselves, but with the models of objects. The main goal of post-non-classical science is the adequacy of the theoretical model to the actual state of af-fairs. Therefore, the truth of the obtained theories can only be relative, and axiological factors are included in the explanation. In other words, the truth of knowledge is not associated with absolute truth, but with social significance.

The classification of the philosopher V. S. Stepin, who divided science into classical, nonclassical and postnonclassical, has a direct relation to a similar classification proposed by Elkonin (1989a, 1989b), who called the cultural-historical theory of L. S. Vygotsky nonclassical psychology. Of course, Elkonin was not a professional science scientist, as Stepin, and his term was introduced, rather, by virtue of intuitive insight. In other words, the term "non-classical psychology" came to us as if from two sides. On the one hand, from a professional philosopher who has been dealing with this problem for many years. On the other hand, from a psychologist.

The L. S. Vygotsky"s theory of speech thinking is a leap into postnonclassical science. Entering into communication with people, we ourselves become an element of this situation. Not just we influence the situation from the outside, but we are inside. As an example, you can name psychotherapy, whose representatives - and, relating to different schools often talking about therapist should consider himself as an element of the psychotherapeutic situation. A person becomes part of a psychological system. And this system should be holistic. For now - it is difficult to explain and in many ways incomprehensible organism. But this is the meaning of the term "post-nonclassical science": I do not just influence the subject of research, but I form a single whole with it. Perhaps, the post-nonclassicism of Vygotsky's theory is best clarified when considering his psychotechnical approach.

- Psychological practice as a psychotechnics.

L. S. Vygotsky believed that in the process of psychological work the internal processes of participants in psychological practice are united. Moreover, a person is always in a state of work, i.e. certainly produces a soulful engagement with the world with tools. But there is no better place to study a man than his workplace, because it is here that the essential forces of a person are revealed in a concentrated form. At the same time, one must bear in mind that the term "labor" did not mean that we, representatives of the consumer society, understand today. In the philistine mind, labor is understood as the process of carrying out some work for money (wages). Marxist philosophers have not analyzed this work. Labor from the point of view of Marxism is a process of transformation of nature. Work 
is the process of creating artifacts, i.e. products of human activity. In this sense, we are constantly in the process of labor, a particular case of which is the ordinary daily work of man. It is here that a psychologist can find his subject in the most "pure", concentrated form. This is the logic of Vygotsky.

But the study of man in the process of labor should not be reduced to the identification of elementary labor movements, as the founders of European and American psychotechnics G. Munstenberg and V. Stern asserted. A psychologist who studies a person must "penetrate" the inner world of a person and try to modify his inner world together with him. How can this be done? Cultural-historical psychology does not give a detailed answer to this question, but L. S. Vygotsky still has some options for this answer.

At an international conference on psychotechnics, held in the early 30's, in the capital of Spain, Madrid, L. S. Vygotsky in the following way reveals the content of his understanding of psychotechnics. In his speech, the creator of cultural-historical psychology calls the study of higher mental functions in the child the main direction of Soviet psychotechnics. It turns out that everything we usually consider as a cultural-historical approach, for Vygotsky himself, is a psychotechnical approach. Psychotechnics for him - not the compilation sequence of the labor action, but the technique of working with the psyche. So psychotechnics must deal with the mediation, systemic, sociality of the inner world of man and the search for compensatory paths that help us overcome difficulties. This means that psychotechnics must form a correct image of the world for a person.

How to form such a correct representation? As an answer to this question, L. S. Vygotsky offers a theory of the zone of proximal development. In accordance with this theory, the student has the opportunity to learn something himself, but he can overcome more difficult questions only with the help of the teacher. What should the teacher do to help the student? Vygotsky believed that the role of the teacher is reduced to an adequate disclosure of the so-called scientific concepts. I think we should add one more point to this. The teacher must create sensible ways of assimilating scientific concepts. In other words, the teacher should be a methodologist, translating scientific concepts into a sensible-perceived form. In particular, P. Galperin argued in his theory of gradual formation of mental actions. Actually, this is the work of psychotechnics - the formation of the student's inner world through the use of sensible learning tools.

In the second half of $20^{\text {th }}$ century an other psychotechnical method was offered by the famous American psychotherapist, one of the creators of humanistic psychology K. Rogers. He called this method - "empathy". Empathy is the penetration of the psychotherapist into the inner world of a person. And it is interaction in the course of interpenetration of spiritual essences of the psychotherapist and the client. As a result, there are two people in each: the client starts to reason as a psychotherapist, and the therapist - as a client.

- The generation of senses as an attribute of man.

An important thesis formulated in the context of the theory of speech thinking is the principle of self-development of the inner world, based on the contradiction between sense 
and significance. Considering the human experience as a unit of psychological analysis, the author of cultural-historical psychology asserts that the subject of psychology is the process of transition from internal to external (exteriorization) and back (interiorization). The result of this process is a constant change of the scope of human senses.

Human experiences are "saturated" not only with its affectivity. Behind the affective field, says L. S. Vygotsky is the life of man. Thus, the unit of psychological analysis (and, therefore, the subject of psychological research) is the bearer of all the experience accumulated by man. Here, the main mystery of man is hidden: in fact, each of us is the bearer of meanings that constitute the existential characteristic of a person.

Thus L. S. Vygotsky comes close to the idea of the production of meanings as the most important function of man. Since the meanings are always unique, individual entities, we approach the issue of understanding and, in particular, mutual understanding of people. Apparently, here we can find a field of possibilities for the introduction of psychology not only in the situation of interpersonal conflicts (this is still one of the spheres of application of the forces of psychologists-practitioners), but also in the system of interstate conflicts, which are based primarily on intercultural differences.

The peculiarities of this mechanism will be revealed to us if we consider the following construct "value as the fifth dimension" formulated by A. N. Leontiev in a posthumously published article devoted to the category Image of the World (1983). We perceive the world, says Leontiev, in its spatial-temporal characteristics. But the world is always perceived in refraction through our meanings. If we perceive the world around us, then this world is not the same for each of us. Each person refracts the world, as if a kind of prism is placed between us and the world. The exteriorized "inner" world, socializing, returns to us and further individualizes our psychological system.

In the concept of "significance as the fifth dimension", Soviet psychology attempted to measure the ideal and material, extended and unextended substances, in the language of R. Descartes, to overcome the Cartesian-Lockean dichotomy, in the terminology of A. N. Leont'ev.

What does it mean to be the fifth dimension? This means that internal attitudes and semantic fields transform spatial and temporal characteristics so that they acquire unexpected and unusual characteristics from the point of view of an outside observer (and sometimes the subject himself). We find convincing empirical evidence of the idea of the "fifth dimension" in various scientific and parascientific studies. We note in this connection the empirical facts obtained in the course of experiments with persevered vision, the placebo effect, repeatedly obtained in the work on the evaluation of medicines, as well as the so-called parapsychological effects, distortions of perception of time in extreme situations. 
- Interaction as an object of natural science.

The subject of psychology should be understood not as a collection of elements, but as a process that generates its elemental base. Not things that have a variety of qualities come into contact with each other, and in the process of interaction things acquire their qualitative certainty. Thus, cultural- historical psychology raises the question before the whole complex of natural sciences: isn't it time to change the initial attitude of all-natural science and to make human interaction researcher and study of nature the starting point of any research?

- Psychology in the system of sciences.

For L. S. Vygotsky, the basic principles are the evolution and sociality of man (this, in fact, allows us to call him a psychological system of cultural-historical). But this is not the two factors, through which a man. It is an integrated system, in accordance with the laws of which the inner world of human senses, which is the main distinguishing feature of the new natural education (let's call this education "people that generate senses" - "Homo sensum"), is a new, qualitatively different natural formation. This novelty consists in the novelty of the laws to which man obeys. Just as in the organic compound, which, of course, obeys the laws of physics, physical laws go to the background, leaving the primacy behind the laws of chemistry, and biological organisms obey the laws of biology, so the laws that govern a person make the laws of physics, chemistry, biology, etc. laws the second level. Hence the conclusion: in front of the psychologists there is a global task of revising the ratio of the Sciences from the standpoint of the rule of laws that govern people.

If we accept the foregoing, then we must admit that the theory of L. S. Vygotsky contains provisions that lead us to the conclusion that it is necessary to transform the entire modern system of views on the system of sciences. Traditionally, the main in this system was physics, as a science dealing with the fundamental elements of the universe, from which the universe "forms", including Homo sapiens. The culturalhistorical paradigm forces us to turn this belief to 1800: we will not come to a new knowledge until we analyze Nature as a product of its interaction with its new formation Homo sensum. Thus, psychology should become the science that will form a new picture of the world.

This position can be illustrated with the help of the well-known classification of sciences by J. Piaget and the similar conception of the Soviet philosopher B. M. Kedrov. These researchers believed that psychology is located in the center of the conditional triangle, the angles of which are social, natural and technical sciences. L. S. Vygotsky's theory allows us to assert that this triangle should from the plane become a spatial figure - a pyramid, the top point of which is occupied by psychology. Of course, such an approach requires a revision of the very foundations of the psychological science, which should turn from an experimental-theoretical into a philosophical-practical one, i.e. engaged in the comprehension of man in its integrity (activities, as called such integrity A. N. Leontiev).

$* * * * *$ 
The development of cultural-historical psychology seems to us not a quantitative, but a qualitative leap that led L. S. Vygotsky to a completely new vision of the subject of psychology. It was this vision that he set out in the last book, Thinking and Speech. Moreover, in the concluding 7th chapter of this book a variant of cultural-historical psychology is presented, which allows us to speak about the transition of its author to a new stage in the development of the theory. The new building of the theory, which, we think, moved toward the existential interpretation of human existence, and remained unfinished. Moreover, it is difficult to say how such a theory could have been created in the conditions of the Stalinist tragedy that was approaching the Soviet Union in the 1930s century.

Our interpretation of Vygotsky's theory, rather, raises many questions than answers. This vision of the subject allows a new light on the relationship between the so-called natural and humanitarian sciences. L. S. Vygotsky tells us: the whole life of a person, the formation of his inner world, occurs by constructing the subject that "adapts" us to an ideal object. Science is only a particular case of this universal law. But even more serious conclusions can be drawn from the psychology of Vygotsky, if we ask ourselves questions directly following from that psychagogical (A. Kronfeld, M. Fuko) approach. One of the main questions: who can teach a new understanding of the world around us? In other words: what is the truth that should be passed on to the disciple? These questions, especially the latter, look utopian. But this does not mean that they are not relevant. And if modern education has allowed the use of the word "competence", then someone should respond to less complicated, and even more dangerous, questions: what competencies should a person have receiving modern, and not only psychological, higher education? Is education reduced to mastering ready-made technologies? Or these technologies should be used only in the context of ideological installations, i.e. in the context of the moral principles on which the existence of human society is built? Hence the direct question: are there any moral limitations for science? Thus, the questions posed in Vygotsky's theory directly lead us to the problem of the ethics of science. In short, Vygotsky's theory is an ideological paradigm that, if it ever overcomes those natural barriers that inevitably must exist in its path, can turn our ideas about man and the ways of its existence. This kind of psychotechnics, I think, can be called a natural-scientific postnonclassical psychology.

Thus, Vygotsky's cultural-historical psychology is represented not simply by one of the scientific theories, but by the postnonclassical methodological system, which contains a noticeable potential for transforming the foundations of the world outlook of mankind. Of course, the traditional thinking of our contemporaries is hardly ready for a rapid change in established opinions. Therefore, I think, L.S. Vygotsky will long be one of the most underappreciated thinkers of the $20^{\text {th }}$ century.

\section{References}

Elkonin, D. B. (1989a). About the sources of non-classical psychology. In D. B. Elkonin (Ed.), Selected psychological works (pp. 475-478). Moscow: Pedagogy.

Elkonin, D. B. (1989b). Vygotsky today. In D. B. Elkonin (Ed.), Selected psychological works 
(pp. 469-475). Moscow: Pedagogy.

Leontiev, A. N. (1983). Image of the world. Selected Works in Psychology.

Stepin, V.S. (2000). Theoretical knowledge: Structure, historical evolution. Moscow: ProgressTradition. 